\title{
Effect of Ambient Air Temperature on the Performance of Steam Generator
}

\author{
Hadyan Fahad Alajmi
}

\begin{abstract}
The aim of this research is to investigate the effect of ambient air temperature on the steam generation. A parametric study was performed based on exergy analysis to study the impact of ambient air temperature on second law of efficiency, irreversibility and adiabatic flame temperature of steam generation. The results showed that at 25 percent excess air and with the range of ambient air temperature from $25 \mathrm{oC}$ to $100 \mathrm{oC}$, the adiabatic flame temperature increases from 2015 oC to 2065 oC. Also the results showed that the second law efficiency and irreversibility ranges from $40.295 \%$ to $40.290 \%$ and 494.063 MJ to 494.161 MJ, respectively as the ambient air temperature increases from $25 \mathrm{oC}$ to $100 \mathrm{oC}$. It is included that the ambient air temperature has a minimum impact on adiabatic flame temperature and insignificant impact on both the second law efficiency and irreversibility of overall steam generation. Also the combustion chamber and heat transfer sections of steam generation were studied by using exergy analysis. It was concluded that the ambient air temperature has a minimum impact on both combustion chamber and heat transfer sections.
\end{abstract}

Index Terms-Exergy, ambient air temperature, irreversibility, second law efficiency, adiabatic flame temperature, excess air.

\section{INTRODUCTION}

The steam generation, frequently called boiler, is used to transfer heat from the products of combustion to water, and produces hot water or steam. The fuel and excess air at ambient air temperature are burned into the combustion chamber and produce hot gases at high temperature. The produced gases are travelled along the heat transfer exchanger to heat the water into steam by radiation and then exhausted to flare stack.

The effect of the variation of ambient air temperature on the performance of steam generation and power plant have been reported by several authors. The combustion chamber is the major contributor for exergy destruction of the power plant followed by heat exchanger of boiler system [1]-[4]. It was observed that decreasing the fraction of excess air from $40 \%$ to $15 \%$ increases the exergy efficiency by $0.37 \%$ of steam power plant [2]. A reduce of $1^{\circ} \mathrm{C}$ temperature of inlet air temperature to the combustion chamber increases the power output of gas turbine plant by approximately $0.7 \mathrm{MW}$ [5]. It is observed that the power of gas turbine decreases with the increase of ambient air temperature due to reduction in air mass flowrate [6]. The ambient temperature play a very important role during the prediction of the performance of

Manuscript received August 3, 2016; revised December 23, 2016.

Hadyan Fahad Alajmi is with Kuwait Oil Company, Kuwait (e-mail: halajmi@kockw.com). combine cycle power plant [7], [8]. It was shown that the exergy destruction in combustion chamber decreases with an increase in ambient temperature from 0.21 to $0.35 \%$ for every ${ }^{\circ} \mathrm{C}$ rise in ambient temperature while the exergy destruction in compressor, gas turbine, HRSG and steam turbine increases with an increase in ambient temperature from 0.32 to $0.35 \%$ for every ${ }^{\circ} \mathrm{C}$ rise in ambient temperature [9]. Also it was observed that the combined cycle loses it efficiency by about $0.04 \%$ for every ${ }^{\circ} \mathrm{C}$ rise in ambient temperature while the gas turbine cycle efficiency decreases by 0.03 to $0.07 \%$ for every ${ }^{\circ} \mathrm{C}$ rise in ambient temperature [9]. It was included that as the ambient air temperature of power plant increases by $35{ }^{\circ} \mathrm{C}$, the net power output from GT is found to be decreased by $24 \%$ and GT plant efficiency is decreased by $9 \%$, while the power output from steam turbine is found to decrease by $9 \%$ [10].

Most of the researchers have used Exergy analysis to evaluate the power plant [2]-[4], [8], [9]. Exergy analysis, which is based on the second law of thermodynamics, has been found to be a potential tool for enhancing the understanding of system performance by determining the amount of irreversibilities. The irreversibility involved in the component of any system can be quantitatively measured with the help of exergy loss. Since the steam generator is the major contributor of the exergy destruction, the focus on this paper will be on steam generator. It is noticed that from literature that researchers have investigated the impact of ambient air temperature on the exergy destruction in the combustion chamber and heat transfer only. Therefore in this paper the impact of ambient air temperature on the exergy destruction in the overall steam generator will be discussed and studied. So the effect of the ambient air temperature on the overall steam generator at different excess air percentages will be discussed in this paper.

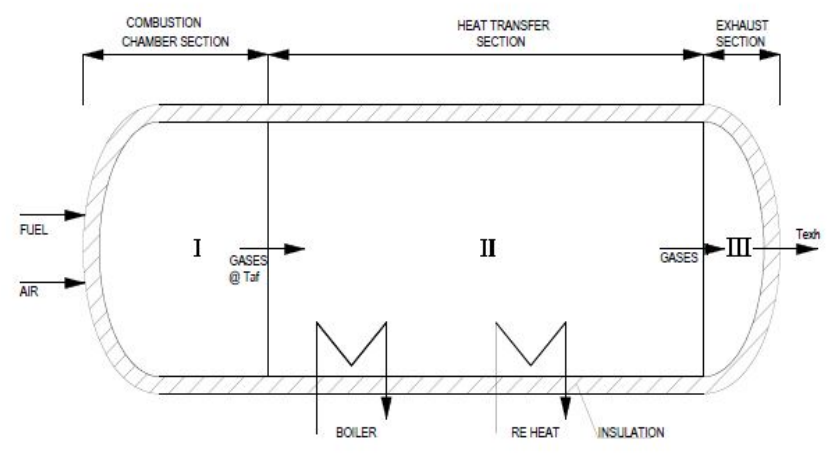

Fig. 1. Schematic diagram of exergy analysis of steam generation. [11].

\section{SYSTEM DESCRIPTION}

The schematic diagram of the exergy analysis of Steam 
Generation system is shown in Fig. 1. The steam generation divided into three section in terms of exergy. The three sections are combustion chamber section, heat transfer section and exhaust section

The values of temperature, pressure of the boiler and reheat are actual data [1]. The fuel assumed to be methane with $25 \%$ excess air. In this paper, the exergy analysis of combustion chamber section, heat transfer section, exhaust section and overall steam generation will be presented

\section{ENERGY AND EXERGY ANALYSIS OF STEAM GENERATION}

The steady flow energy balance for adiabatic combustion when the changes in kinetic and potential energies are negligible is as follows [11]

$$
\Sigma_{\mathrm{p}} \mathrm{N}_{\mathrm{i}}\left(\mathrm{h}_{\mathrm{f}, \mathrm{o}}+\mathrm{h}_{\mathrm{T} @ \mathrm{af}}+\mathrm{h}_{\mathrm{o}}\right)=\Sigma_{\mathrm{R}} \mathrm{N}_{\mathrm{i}}\left(\mathrm{h}_{\mathrm{f}, \mathrm{o}}+\mathrm{h}_{\mathrm{T} @ \mathrm{af}}+\mathrm{h}_{\mathrm{o}}\right)
$$

The exergy analysis of combustion chamber:

The total availability of product gases $(\mathrm{kJ})$ leaving the combustion chamber can be calculated as follows [11]

$$
\begin{gathered}
\Psi_{\mathrm{P} @ \mathrm{Taf}}=\Sigma_{\mathrm{p}} \mathrm{N}_{\mathrm{i}}\left[\mathrm{h}_{@ \mathrm{Taf}}-\mathrm{h}_{@ \mathrm{To}}-\mathrm{T}_{\mathrm{o}}\left(\mathrm{S}_{@ \mathrm{Taf}}-\mathrm{S}_{@ \mathrm{To}}\right)\right]+\mathrm{RT} \mathrm{T}_{\mathrm{o}} \Sigma_{\mathrm{i}} \mathrm{N}_{\mathrm{i}} \\
\ln \left(\mathrm{y}_{\mathrm{i}} / \mathrm{y}_{\mathrm{i}, 00}\right)
\end{gathered}
$$

The exergy of fuel $(\mathrm{kJ})$ and air can be calculated as follows

$$
\begin{gathered}
\Psi_{\mathrm{f}}=\mathrm{MW}_{\mathrm{CH} 4} * 1.05 * \mathrm{LHV} \\
\Psi_{\mathrm{a}}=4.76 \mathrm{~N}_{\mathrm{a}}\left[\left(\mathrm{h}_{@ \mathrm{Ta}}-\mathrm{h}_{@ \mathrm{To}}\right)-\mathrm{T}_{\mathrm{o}}\left(\mathrm{S}_{@ \mathrm{Ta}}-\mathrm{S}_{@ \mathrm{To}}\right)\right]
\end{gathered}
$$

The combustion irreversibility $(\mathrm{kJ})$ and second law efficiency of combustion (\%) can be calculated as follows [11]

$$
\begin{aligned}
& \mathrm{I}_{\mathrm{comb}}=\left(\Psi_{\mathrm{a} @ \mathrm{Ta}}+\Psi_{\mathrm{f}}\right)-\Psi_{\mathrm{P} @ \mathrm{Tdf}} \\
& \varepsilon_{\mathrm{comb}}=\Psi_{\mathrm{P} @ \mathrm{Tdf}} /\left(\Psi_{\mathrm{a} @ \mathrm{Ta}}+\Psi_{\mathrm{f}}\right)
\end{aligned}
$$

The exergy analysis of Heat Transfer Section:

The boiler first law efficiency $(\mathrm{kJ})$ as follows

$$
\mathrm{Q}_{\mathrm{b}, \mathrm{rh}}=\mathrm{M}_{\mathrm{b}}\left(\mathrm{h}_{\mathrm{e}}-\mathrm{h}_{\mathrm{i}}\right)_{\mathrm{b}}+\mathrm{M}_{\mathrm{rh}}\left(\mathrm{h}_{\mathrm{e}}-\mathrm{h}_{\mathrm{i}}\right)_{\mathrm{rh}}
$$

The exergy output of boiler $(\mathrm{kJ})$ as follows

$$
\Psi_{\mathrm{b}, \mathrm{rh}}=\mathrm{M}_{\mathrm{b}}\left(\Psi_{\mathrm{e}}-\Psi_{\mathrm{i}}\right)_{\mathrm{b}}+\mathrm{M}_{\mathrm{rh}}\left(\Psi_{\mathrm{e}}-\Psi_{\mathrm{i}}\right)_{\mathrm{rh}}
$$

The heat transfer irreversibility $(\mathrm{kJ})$ and second law efficiency of heat transfer $(\%)$ can be calculated as follows [11]

$$
\begin{aligned}
& \mathrm{I}_{\mathrm{ht}}=\left(\Psi_{\mathrm{p} @ \mathrm{Tdf}}-\Psi_{\mathrm{P} @ \mathrm{Texh}}\right)-\Psi_{\mathrm{b}, \mathrm{rh}} \\
& \varepsilon_{\mathrm{ht}}=\Psi_{\mathrm{b}, \mathrm{rh}} /\left(\Psi_{\mathrm{p} @ \mathrm{Tdf}}-\Psi_{\mathrm{P} @ \mathrm{Texh}}\right)
\end{aligned}
$$

The exergy analysis of exhaust section:
The total availability of product gases $(\mathrm{kJ})$ leaving to flare stack can be calculated as follows [11]

$$
\begin{gathered}
\Psi_{\mathrm{P} @ \mathrm{Texh}}=\Sigma_{\mathrm{p}} \mathrm{N}_{\mathrm{i}}\left[\mathrm{h}_{@ \mathrm{Texh}}-\mathrm{h}_{@ \mathrm{To}}-\mathrm{T}_{\mathrm{o}}\left(\mathrm{S}_{@ \mathrm{Texh}}-\mathrm{S}_{@ \mathrm{To}}\right)\right]+\mathrm{RT}_{\mathrm{o}} \Sigma_{\mathrm{i}} \mathrm{N}_{\mathrm{i}} \\
\ln \left(\mathrm{y}_{\mathrm{i}} / \mathrm{y}_{\mathrm{i}, 00}\right) \\
\mathrm{I}_{\mathrm{exh}}=\Psi_{\mathrm{P} @ \mathrm{Texh}}
\end{gathered}
$$

The exergy analysis of overall steam generation:

The steam generation irreversibility $(\mathrm{kJ})$ and second law efficiency of steam generation $(\%)$ can be calculated as follows [11]

$$
\begin{aligned}
& I_{\mathrm{st}}=\left[\left(\Psi_{\mathrm{a} @ \mathrm{Ta}}+\Psi_{\mathrm{f}}\right)-\Psi_{\mathrm{P} @ \mathrm{Texh}]}-\Psi_{\mathrm{b}, \mathrm{rh}}\right. \\
& \varepsilon_{\mathrm{st}}=\Psi_{\mathrm{b}, \mathrm{rh}} /\left[\left(\Psi_{\mathrm{a}} @ \mathrm{Ta}\right.\right. \\
& \left.\left.+\Psi_{\mathrm{f}}\right)-\Psi_{\mathrm{P} @ \mathrm{Texh}}\right]
\end{aligned}
$$

\section{RESULTS AND DISCUSSIONS}

The parametric study was performed based on the exergy analysis to study the effect of ambient air temperature on the steam generation. The parametric study was performed and the calculations were presented at humidity ratio of $80 \%$. The study investigated the effect of ambient air temperature on the adiabatic flame temperature, irreversibility and second law efficiency of overall steam generation as well as the major sources of irreversibilities in the steam generation such as combustion chamber section and heat transfer section.

The effect of ambient air temperature on the second law efficiency of steam generation at different values of excess air is show Fig. 2. The results are obtained at humidity ratio of $80 \%$ and at four different excess air percentages; $0,25,50$, and $100 \%$. The fuel was assumed to be at the ambient temperature of $25^{\circ} \mathrm{C}$ and $1 \mathrm{~atm}$. As shown in Fig. 2, the second law efficiency is insensitive to ambient air temperature, for instance at excess air of $25 \%$, the second law efficiency of steam generation ranges from $40.295 \%$ to 40.290 as the ambient air temperature increases from $25^{\circ} \mathrm{C}$ to $100{ }^{\circ} \mathrm{C}$. Also the results have showed that as the excess air percentages increase the second law efficiency of combustion chamber decrease. This is behavior due to the decrease of adiabatic flame temperature as the excess air percentage increase.

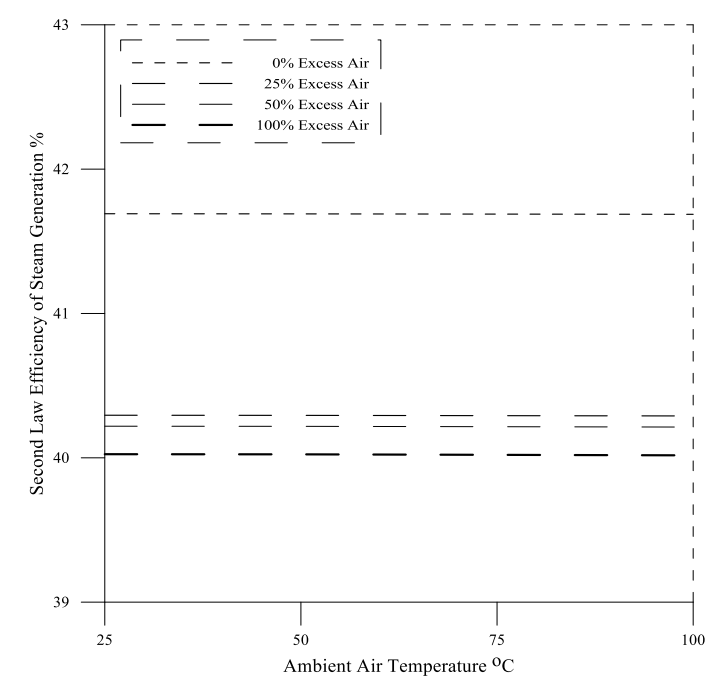

Fig. 2. Effect of ambient air temperature on the second law efficiency of steam generation at different excess air percentages. 
The effect of ambient air temperature on irreversibility of steam generation at different values of excess air is show Fig. 3. The results are obtained at humidity ratio of $80 \%$ and at four different excess air percentages; 0, 25, 50, and $100 \%$. The fuel was assumed to be at the ambient temperature of 25 ${ }^{\circ} \mathrm{C}$ and 1 atm. As shown in Fig. 4, the irreversibility is insensitive to ambient air temperature, at excess air of $25 \%$, the irreversibility ranges from 494.063 MJ to 494.161 MJ. It increases with an increase of ambient air temperatures. Also the results have showed that as the excess air percentages increase the irreversibility of combustion chamber increase. This is behavior due to the decrease of adiabatic flame temperature as the excess air percentage increase.

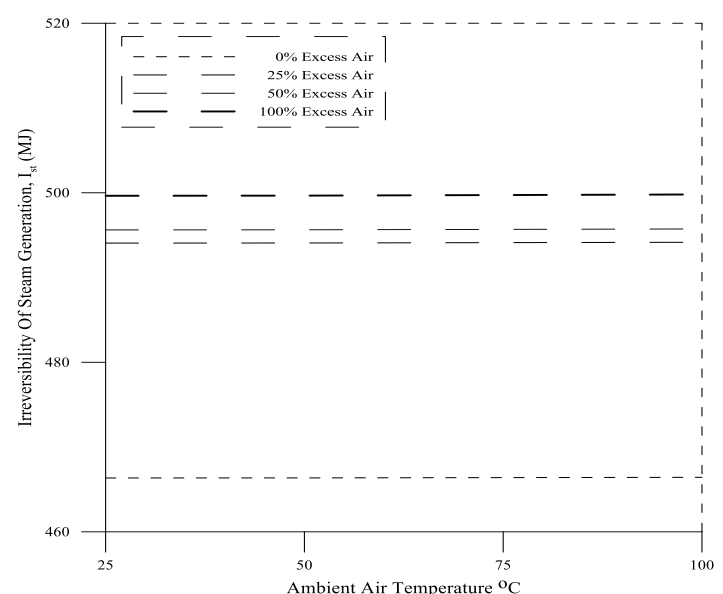

Fig. 3. Effect of ambient air temperature on irreversibility of steam generation at different excess air percentages.

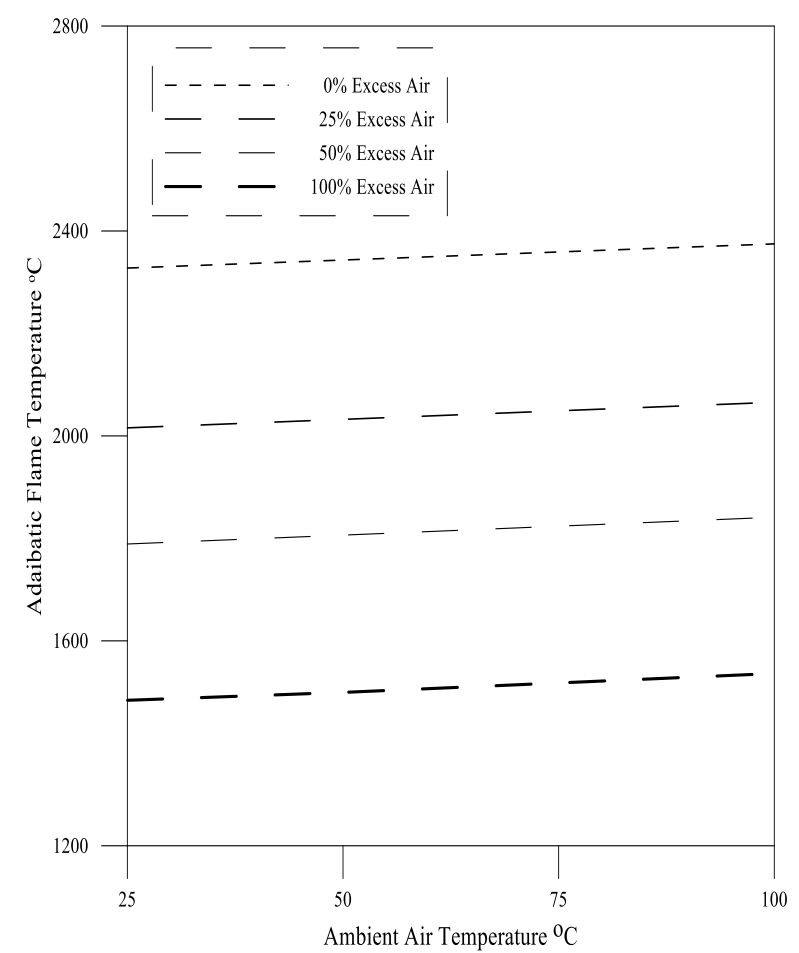

Fig. 4. Effect of ambient air temperature on adiabatic flame temperature at different excess air percentages.

The effect of ambient air temperature on the adiabatic flame temperatures at different values of excess air is show Fig. 4. The results are obtained at humidity ratio of $80 \%$ and at four different excess air percentages; $0,25,50$, and $100 \%$. The fuel was assumed to be at the ambient temperature of 25 ${ }^{\circ} \mathrm{C}$ and $1 \mathrm{~atm}$. As shown in Fig. 4, the effect of ambient air temperature on adiabatic flame temperature is minimum. As the ambient air temperature increases the adiabatic flame temperature increases. The figure also shows that as the excess air increases the adiabatic flame temperature decreases.

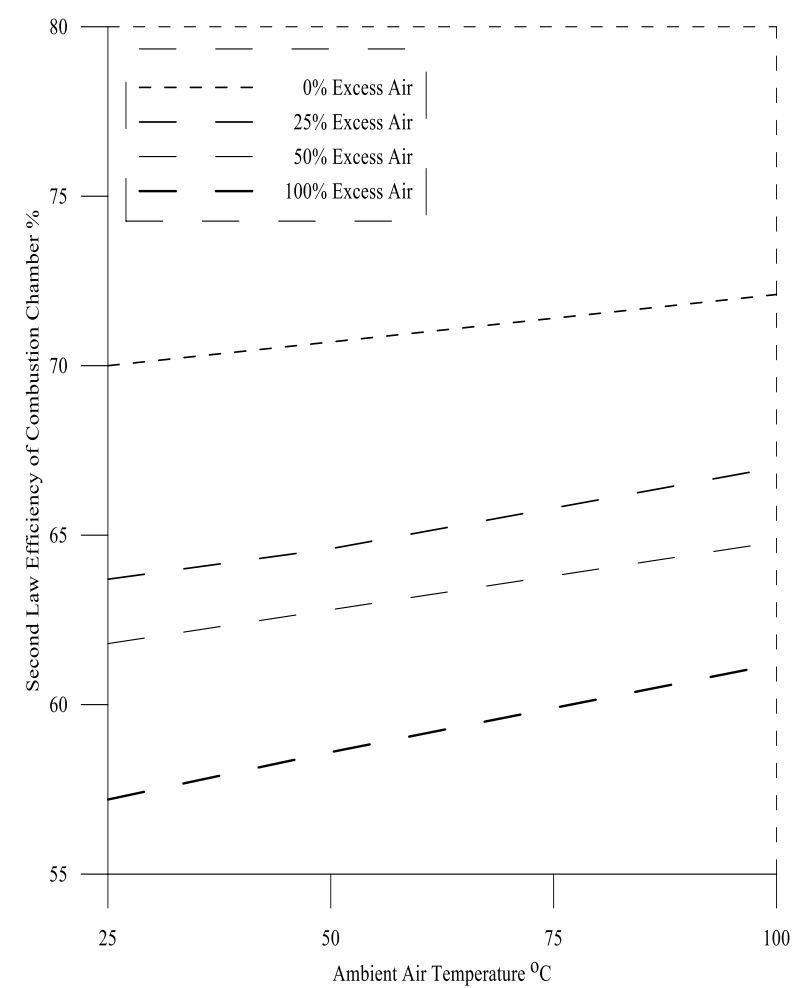

Fig. 5. Effect of ambient air temperature on the second law efficiency of combustion chamber section at different excess air percentages.

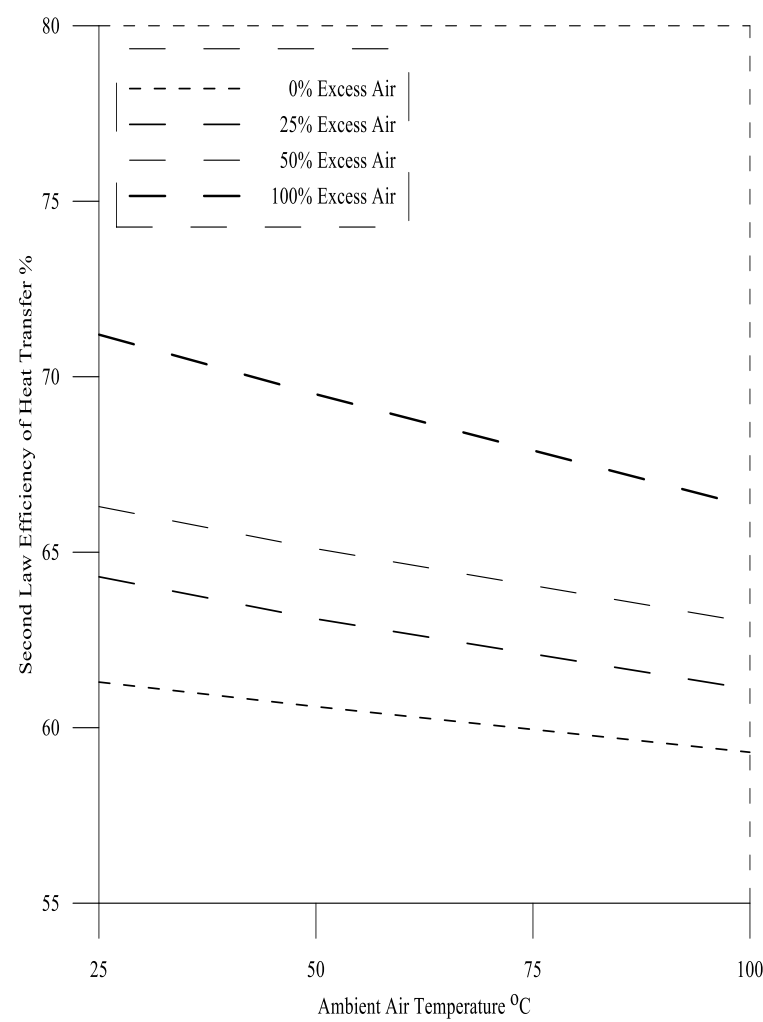

Fig. 6. Effect of ambient air temperature on the second law efficiency of heat transfer section at different excess air percentages.

The effect of ambient air temperature on the second law efficiency of combustion chamber at different values of excess air is show Fig. 5. The results are obtained at humidity 
ratio of $80 \%$ and at four different excess air percentages; 0 , 25,50 , and $100 \%$. The fuel was assumed to be at the ambient temperature of $25^{\circ} \mathrm{C}$ and $1 \mathrm{~atm}$. As shown in Fig. 5, at excess air of $25 \%$, the second law efficiency of combustion chamber ranges from $63.7 \%$ to $67 \%$. It increases with the increase of ambient air temperature from $25^{\circ} \mathrm{C}$ to $100{ }^{\circ} \mathrm{C}$. This behavior due to the increase in the adiabatic flame temperature. Also as shown in Fig. 5, at ambient air temperature of $25^{\circ} \mathrm{C}$, the second law efficiency of combustion chamber ranges from $70 \%$ to $57.2 \%$. It decreases with the increase of excess air from $0 \%$ to $100 \%$. This behavior is due to the decrease of adiabatic flame temperature.

The effect of ambient air temperature on the second law efficiency of heat transfer section of steam generation at different values of excess air is show Fig. 6. The results are obtained at humidity ratio of $80 \%$ and at four different excess air percentages; $0,25,50$, and $100 \%$. The fuel was assumed to be at the ambient temperature of $25^{\circ} \mathrm{C}$ and 1 atm. As shown in Fig. 6, at excess air of $25 \%$, the second law efficiency of heat transfer section ranges from $64.3 \%$ to $61.1 \%$. It decreases with the increase of ambient air temperature from $25{ }^{\circ} \mathrm{C}$ to $100{ }^{\circ} \mathrm{C}$. This behavior is due to the increase of adiabatic flame temperature, which yield to a increase in the temperature difference between the steam temperature and the adiabatic flame temperature. Also as shown in Fig. 5, at ambient air temperature of $25^{\circ} \mathrm{C}$, the second law efficiency of heat transfer section ranges from $61.3 \%$ to $71.2 \%$. It increases with the increase of excess air from $0 \%$ to $100 \%$. This behavior is due to the decrease of adiabatic flame temperature, which yield to a decrease in the temperature difference between the steam temperature and the adiabatic flame temperature.

\section{CONCLUSIONS}

The present research has investigated the impact of ambient air temperature, which ranges from $25{ }^{\circ} \mathrm{C}$ to $100{ }^{\circ} \mathrm{C}$, at four different excess air percentages; 0, 25, 50, and 100\% on adiabatic flame temperature, second law efficiency of combustion chamber section and heat transfer section of steam generation and also the overall irreversibility and second law efficiency of steam generation. The calculations were based on Exergy analysis. The results showed that the ambient air temperature has insignificant impact on the second law efficiency and irreversibility of overall steam generation and while it has a minimum impact on adiabatic flame temperature. It was also concluded that the second law efficiency of combustion chamber increases with the increase of ambient air temperature while the second law efficiency of heat transfer decreases with the increase of ambient air temperature. However, the impact of ambient air temperature on both combustion chamber section and heat transfer section is minimum.

\section{NOMENCLATURE}

\footnotetext{
$R:$ Gas Constant, $\mathrm{kJ} \mathrm{kg}^{-1} \mathrm{~K}^{-1}$

T: Temperature, ${ }^{\circ} \mathrm{C}$

$h$ : Enthalpy, kJ

$\mathrm{y}$ : Mole fraction
}

\author{
$L H V$ : Low Heating Value, $\mathrm{kJ} \mathrm{kg}^{-1}$ \\ $N$ : Number of Moles, kmol \\ $M W$ : Molecular Weight \\ $C_{p}$ : Specific Heat, $\mathrm{kJ} \mathrm{kg}^{-1}$ \\ Greek Symbols \\ $\mathcal{E}$ : Second Law Efficiency, \% \\ $\Psi$ : Exergy, kJ \\ Subscript \\ a: air \\ $f$ : Fuel \\ fo: Formation \\ af: Adiabatic Flame \\ comb: Combustion Chamber \\ $h t$ : Heat Transfer \\ exh: Exhaust \\ $b$ : Boiler \\ $r h$ : Reheat \\ $o$ : Surrounding \\ 00: Environmental \\ $P$ : Product \\ $R:$ Reactant
}

\section{REFERENCES}

[1] H. F. Alajmi, "Exergy analysis of steam generation and MSF desalination at Azzour south cogeneration plant," Master thesis, Kuwait University, Kuwait, 2003.

[2] V. Amir, "Improving steam power plant efficiency through exergy analysis: Ambient temperature," presented at $2^{\text {nd }}$ International Conference on Mechanical, Production and Automobile Engineering (ICMPAE2012), Singapore, April 28-29, 2012.

[3] R. Asadi and M. Arefi, "Thermodynamic analysis available performance characteristic of a heavy duty gas turbine, parametric study of an irreversible cycle model," REFFF Resources Assessment and Management Technical Paper, vol. 32, no. 5, 2012.

[4] M. K. Pal, H. Chandra, and A. Arora, "Second law analysis of gas based thermal power plant to improve its performance," International Journal of Scientific Research and Management (IJSRM), vol. 2, issue 3, pp. 682-688, 2014.

[5] V. Gopinath and G. Navaneethakrishnan, "Performance evaluation of gas turbine by reducing the Inlet air temperature," International Journal of Technology Enhancements and Emerging Engineering Research, vol. 1, issue 1, 2013.

[6] N. Farouk, L. Sheng, and Q. Hayat, "Effect of ambient temperature on the performance of gas turbines power plant," International Journal of Computer Science Issues, vol. 10, issue 1, no. 3, January 2013.

[7] K. P. Tyagi and M. N. Khan, "Effect of gas turbine exhaust temperature, stack temperature and ambient temperature on overall efficiency of combine cycle power plant," International Journal of Engineering and Technology, vol. 2, no. 6, pp. 427-429, 2010.

[8] M. Ameri, and P. Ahmadi, "The study of ambient temperature effects on exergy losses of a heat recovery steam generator," presented at International Conference on Power Engineering, October 23-27, 2007, Hangzhou, China.

[9] A. K. Tiwari, M. M. Hassan, and M. Islam, "Effect of ambient temperature on the performance of a combined cycle power plant," Canadian Society for Mechanical Engineering, vol. 37, no. 4, 2013.

[10] S. Singh and R. Kumar, "Ambient air temperature effect on power plant performance," International Journal of Engineering Science and Technology (IJEST), vol. 4, no. 8, August 2012.

[11] T. J. Kotas, "The exergy method of thermal plant analysis," Butterworths, 1985.

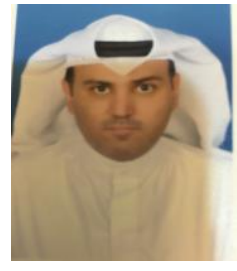

Hadyan Fahad Al-Ajmi comes from Kuwait. He had got the bachelor \& master degrees in mechanical engineering from Kuwait University in 1998 \& 2003, respectively. Also, he has a master degree in petroleum engineering from Southern California University in 2012. He is working in Kuwait Oil Company, started in 1998 as an estimator engineer. Next, From June 2004 to August 2009, he worked as a 
construction engineer. He promoted in August 2009 to be a senior major project engineer, which is his current job now. He published a paper with a title of "Exergetic destruction in steam generation system azzour plant" in the Journal of Exergy. He also participated in Pipeline Coating Conference 2014 in Vienna with a paper title of case study: use of high density polyethylene (HDPE) liners for high pressure effluent water injection pipeline. $\mathrm{He}$ presented a paper on "Effect of ambient air temperature on the performance of gas turbine in $4^{\text {th }}$ International Conference on Chemical and Biological Processes 2015 and now currently in the process of publication. In addition to his participation in International Water Technology Conference, 2010 with a paper title of Integration of TVC Desalination System with Cogeneration Plant: Parametric Study. 